\title{
Researcher sues university over rights to transgenic technology
}

[SAN DIEGO] A legal dispute has blown up over the rights to a potentially valuable technique developed at the University of Hawaii for introducing foreign genes into living organisms.

Anthony Perry, a molecular embryologist formerly at the Babraham Institute in Britain who has been working with Ryuzo Yanagimachi's renowned mouse-cloning team at Hawaii, is suing the university over exploitation of the novel transgenic technique. The technology could have broad applications in genetically engineering mammals to produce human substances (see Nature 394, 408; 1998).

In a lawsuit filed in state court in Honolulu last month, Perry alleges that the university improperly licensed the technology to a small biotechnology firm without his permission. He has asked the court to rule on the university's actions and to rectify alleged violations.

Walter Kirimitsu, Hawaii's general counsel, says that the university holds exclusive patent rights and title to the transgenic technology, and licensed it appropriately. The university will respond to Perry's lawsuit in court next week, and a judge will consider the legal arguments at subsequent hearings.

Although disputes involving patent rights and universities are not uncommon, the case could stir considerable controversy, given the volatility of public attitudes towards genetic engineering and cloning experiments.

The disputed technology is called 'mammalian transgenesis by intracytoplasmic sperm injection', or ICSI transgenesis. It was reported in a paper in May in Science by the so-called 'Team Yana', with Perry as the lead author (see Science 284, 1180-1183; 1999).

Last year, the team reported full development of mice from a cloning technique (see Nature 394, 369-374; 1998). Although the current legal dispute centres on the novel transgenic method, it may in future envelop the team's cloning process as well.

In court records, Perry claims that it was he who invented the transgenic technology, along with other novel methods employed by the team. The technology can be used to genetically engineer animals — such as pigs, cattle or sheep - to produce human hormones or proteins, or drugs.

Typically, a US university owns the rights to any technology developed by its scientists, while the patent bears the name of the scientific inventor once the lengthy filing process is completed. The university can negotiate with a company or organization for develop- ment of a technology. The university and scientific inventors then share the royalties from any commercial product.

In the current dispute, however, Perry who was not employed by the university at the time - says in court records that the university licensed the transgenesis technology without his consent. He also questions the university's title to the technology, and seeks title to the technology for development through a company with which he is associated.

The circumstances have been complicated by the fact that Perry's work in Hawaii was carried out while he was a European Molecular Biology Organization fellow. Another key author of the Science and Nature papers is Teruhiko Wakayama, who was in Hawaii as a fellow of the Japanese Society for the Promotion of Science before joining the university late last year.

After leaving his post at the Babraham Institute in Cambridge, Perry sought to join the university as well. But his hiring has been suspended pending the outcome of the dispute. Funding for Yanagimachi's laboratory comes from the US National Institutes of Health.

The University of Hawaii licensed tech- nological inventions from Yanagimachi's lab to ProBio, a company headed by Australian businessman Laith Reynolds of Perth. Ironically, it was Perry who first proposed a university deal with Reynolds. But Reynolds and Perry have since fallen out, reportedly after Perry became upset that the role of the scientists involved in the early experiments was being minimized.

Reynolds calls Perry's legal action "disingenuous", and adds: "We are continuing with our commercial activities while the university sorts out its problems with one of its staff."

Perry and Wakayama have since formed their own company, BiogeneSys International LLC, with funding from John Henry Felix, a member of the board of trustees of the Salk Institute in La Jolla, California. Perry and Felix - a well-connected Honolulu politician and former owner of a chain of mortuaries - have sought to add Salk scientists to their firm's scientific advisory board.

As the civil lawsuit began, Perry's attorney asked a Hawaii administrative court to declare void the university's deal with ProBio, arguing that it violated state procurement law. An administrative judge is expected to rule soon on that request.

RexDalton

\section{CERN collider homes in on Higgs boson}

[MUNICH] Scientists at the European Laboratory for Particle Physics (CERN) are celebrating a breakthrough which some claim could in principle allow them to produce and begin to characterize the elusive Higgs boson before the end of this year.

Over the past three years, CERN's Large Electron-Positron Collider (LEP) in Geneva, the world's most powerful particle accelerator, has been tuned to deliver higher and higher energy beams. Last week, almost exactly ten years after its first experiments, LEP was pushed beyond its design limits when its colliding beams of electrons and positrons achieved energies of $200 \mathrm{GeV}$ (individual beam energies of $96 \mathrm{GeV}$ were reached in May, and $98 \mathrm{GeV}$ in July).

This achievement could, say some physicists, be sufficient to detect the Higgs boson, the particle physicist's Holy Grail. Recent measurements at LEP predict a mass of around $109 \mathrm{GeV}$ for the standard model Higgs boson - a particle whose existence was hypothesized to explain why all other particles have such a wide range of masses.

Not everyone is confident that the Higgs mass will be quite so low, and the boson may therefore remain elusive until the

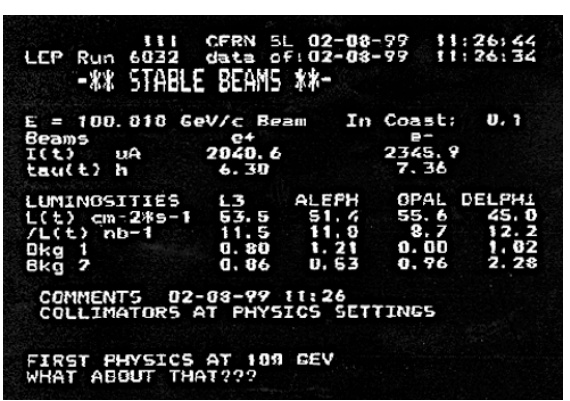

Into the record book: LEP report on the first collisions at $200 \mathrm{GeV}$ centre-of-mass energy.

construction of CERN's Large Hadron Collider. But the response among CERN scientists when LEP hit its energy target "was quite noisy", says Patrick Janot, the collider's physics coordinator. "We opened all our champagne bottles at the same time."

Mike Witherell, new director of the US particle physics laboratory Fermilab, describes it as a "great achievement to be able to squeeze so much physics out of LEP". $\mathrm{He}$ adds that the Higgs mass is "so fundamental to our field" that every increase in $\mathrm{GeV}$ is very important to home in more precisely on the likely mass.

Alison Abbott 